\title{
Health system loath to innovate, experts say
}

I $\mathrm{t}$ has become a truism in Canada that when health experts gather, they will inexorably conclude that the health care system needs reform, transformation, a redistribution of resources to put more money in pocket $\mathrm{X}$ as opposed to pocket $\mathrm{Y}$, etcetera, etcetera.

Even the experts, including several attending the first Summit on Sustainable Health and Health Care, which commenced yesterday in Toronto, Ontario, appear weary of the relentless reiterations of the need for reform.

"I'm tired of research reports and media talking about what's wrong with the Canadian health system and what I really want to get on to is: When we are going to get on with transformation?" said Paddy Meade, CEO of the Institute for Health System Transformation \& Sustainability in Vancouver, British Columbia. "I'm calling on a revolution for those of you that would like to join; change the language and change the engagement. It's no longer about a system we're not satisfied with. It's really about change."

But summit delegates were quickly reminded that there are major impediments to change, not the least of which is that many in the health care system are loathe to change, whether because they are protecting vested interests or are simply risk-adverse.

Health care seems no different than many other sectors of the Canadian economy in that it is hardly innovative, said Daniel Muzyka, president and CEO of the Conference Board of Canada, which sponsored the summit.

But the system's reluctance to innovate has dramatic consequences on economic productivity, Muzyka argued. Health care spending, which the Canadian Institute for Health Information projects will reach $\$ 207$ billion in 2012 , accounts for about $12 \%$ of gross domestic product while employing roughly two million people, he noted.

But estimates of the economic impact of poor population health are as high as

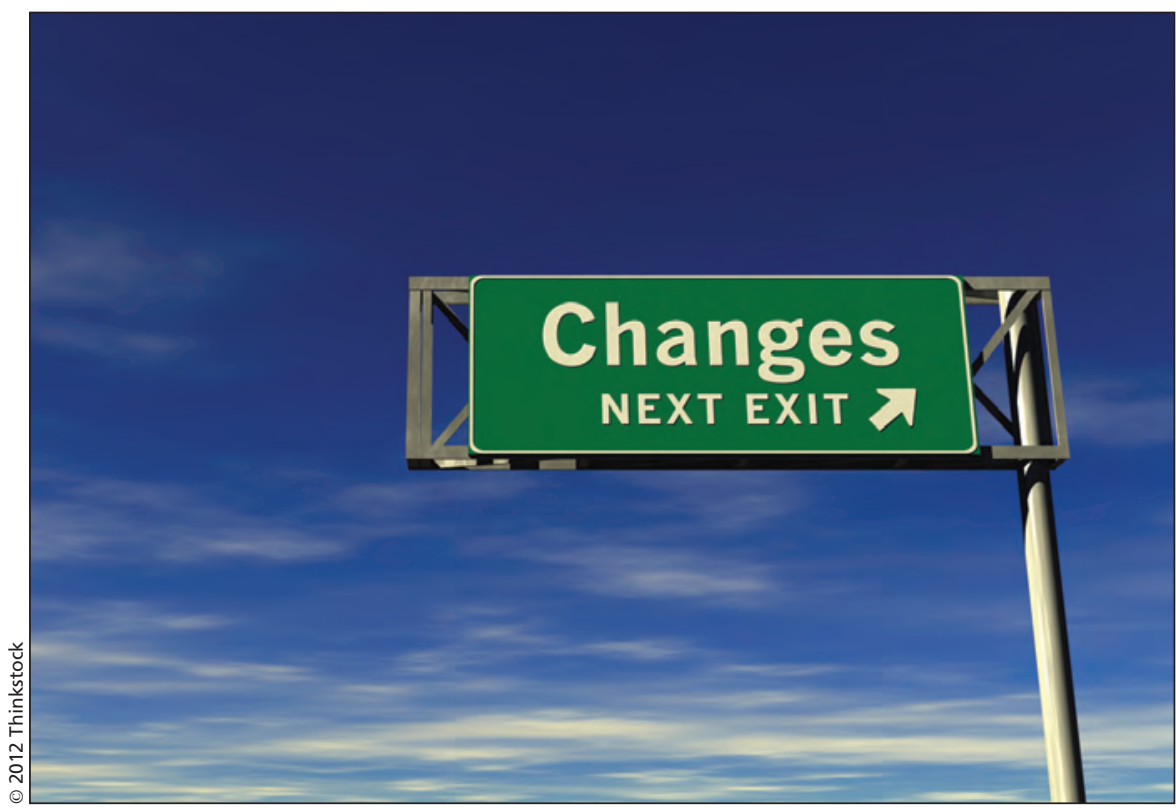

There is a consensus that change is needed in the health care system but where exactly that will lead is unclear.

\$21 billion per year, Muzyka noted. As a consequence, "a debate on health care reform is a debate on Canada's future prosperity. Canada lags in innovation and that is the single largest factor in declining competitiveness."

Among systemic deficiencies that must be addressed are the dismal level of use of information technologies; the provision of mental health services; and the provision of health care to Aboriginal, poor and aging populations, he said, adding that other issues that must be addressed include demographic trends such as rising levels of childhood obesity, as well as appropriate models for delivering primary care, including the role of the private sector in doing so.

"Making incremental improvements in the delivery of care and realizing bold new visions, making giant leaps, sharing incremental steps that work and implementing them throughout the system requires us to look at many levels for improvement," he said.

Others argued that the Canadian system needs to address the actual nature of the care it provides, particularly in light of demographic developments and the growing incidence rate of chronic diseases.

"By 2015, we will have more old people than young people," said Dr. R. Alejandro Jadad, founder of the Centre for Global eHealth Innovation. "We continue to deliver care based on single organs or single diseases. We don't even know how to treat multiple chronic diseases."

As well, health care costs could be reduced if the system paid more attention to management of symptoms in the treatment of patients with incurable diseases, such as fatigue in patients with cancer, Jadad argued. "We send people on a continuous carousel of appointments and what is bothering them for most of the time is symptom management. ... We're all going to die and we tend not to talk about how we die. We don't have a clue about when we die. We don't have a clue about how we're dying. Most of us are dying in hospital facilities, full of symptoms."

Others argued that the sustainability of the health care system will require major injections of new money. To 
ensure "timely access" to care, Canada may have to hike taxes, said Dr. Irfan Dhalla, an assistant professor at the University of Toronto and a physician at St. Michael's Hospital.

Still others contended the solution to the sustainability puzzle lies in ongoing reform of primary care models and in greater use of home and community care. "We're living longer but there are a greater number of people with chronic conditions, 70 to $80 \%$ of activities could be better done outside of hospitals," said Gaétan Lafortune, a senior economist with the
Organisation for Economic Co-operation and Development.

Canadian Medical Association President Dr. Anna Reid contended that it will take a collaborative effort to achieve reform. "It's important to have businesses, government, researchers and patients at the same table. All of us have an interest in the health care system being effective, consistent and sustainable,"

Transformation of the system is a "Canada-wide problem" which will require measures to ensure that the cost of pharmaceuticals, long-term care and home care falls under the rubric of universal care, she added.

Canada must also address the underlying social determinants of health, Reid said. "Almost one million Canadians a month visit a food bank, 300000 don't have homes and 1.3 million live in substandard housing. These people pay a cost with their health and are a burden on our health care system ... They're more likely to be hospitalized and have mental health issues and more likely to die earlier." - Adam Miller, CMAJ

CMAJ 2012. DOI:10.1503/cmaj.109-4335 